\title{
Bidirectional band-selective magnetization transfer along the protein backbone doubles the information content of solid-state NMR correlation experiments
}

\author{
M. M. Jolly ${ }^{1}$ J. A. Jarvis ${ }^{1}$ - M. Carravetta ${ }^{2}$ M. H. Levitt ${ }^{2}$ P. T. F. Williamson ${ }^{1}$ (I)
}

Received: 24 June 2017 / Accepted: 21 October 2017 / Published online: 8 November 2017

(c) The Author(s) 2017. This article is an open access publication

\begin{abstract}
Resonance assignment is the first stage towards solving the structure of a protein. This is normally achieved by the employment of separate inter and intra residue experiments. By utilising the mixed rotation and rotary recoupling (MIRROR) condition it is possible to double the information content through the efficient bidirectional transfer of magnetization from the $\mathrm{CO}$ to its adjacent $\mathrm{C} \alpha$ and the $\mathrm{C} \alpha$ of the subsequent amino acid. We have incorporated this into a 3D experiment, a 3D-MIRROR-NCOCA, where correlations present in the 3D spectrum permit the sequential assignment of the protein backbone from a single experiment as we have demonstrated on a microcrystalline preparation of GB3. Furthermore, the low-power requirements of the MIRROR recoupling sequence facilitate the development of a low-power 3D-NCOCA experiment. This has enabled us to realise significant reductions in acquisition times, allowing the acquisition of a single 3D-NCOCA spectrum suitable for a full backbone resonance assignment of GB3 in less than $24 \mathrm{~h}$.
\end{abstract}

Keywords MIRROR $\cdot$ GB3 $\cdot$ DARR $\cdot$ Sequential assignment $\cdot$ Protein NMR $\cdot$ Solid-state

Electronic supplementary material The online version of this article (doi:10.1007/s10858-017-0147-0) contains supplementary material, which is available to authorized users.

P. T. F. Williamson

P.T.Williamson@soton.ac.uk

1 Centre for Biological Sciences, University of Southampton, Southampton SO17 1BJ, UK

2 School of Chemistry, University of Southampton, Southampton SO17 1BJ, UK

\section{Introduction}

Over the past two decades, significant advances have been made in techniques for the determination of the atomicresolution structure and dynamics of proteins by solidstate NMR (ssNMR). This is due in part to technological advances in hardware, leading to the availability of higher magnetic fields, and faster spinning MAS probes; as well as a plethora of methodological advances and pulse sequences to determine the structure of large biopolymers.

A prerequisite for site-specific structural and dynamic studies of proteins by ssNMR is a backbone resonance assignment. While proton-detected methods of resonance assignment and structure determination are becoming increasingly more popular and less time consuming with the advent of ultrafast MAS $(>60 \mathrm{kHz})$ probes (Andreas et al. 2016; Marchetti et al. 2012; Barbet-Massin et al. 2014; Wang et al. 2015; Agarwal et al. 2014), the assignment process is still commonly achieved using ${ }^{13} \mathrm{C}$-detected experiments on uniformly ${ }^{13} \mathrm{C} /{ }^{15} \mathrm{~N}$ labelled samples at rotation frequencies below $60 \mathrm{kHz}$ (Theint et al. 2017; Ravotti et al. 2016; Wiegand et al. 2016; Schnell 2005, Su et al. 2014). Though other approaches are used, the most common method to assign the protein backbone with ${ }^{13} \mathrm{C}$-detected experiments is to use separate two- and three-dimensional heteronuclear NCC correlation experiments of the type NCOCA/NCOCX to obtain inter-residue correlations, and NCACO/NCACX to obtain intra-residue correlations, usually in combination with other two- and three-dimensional hetero- and homonuclear experiments (Pauli et al. 2001; Sperling et al. 2010; Schuetz et al. 2010; Higman et al. 2009). NCOCX and NCACX experiments are both typically performed with band selective polarisation transfer by cross-polarisation (CP) from ${ }^{15} \mathrm{~N}_{\mathrm{i}}$ spins to either adjacent $\mathrm{CO}_{\mathrm{i}-1}(\mathrm{NCOCX})$ or $\mathrm{C} \alpha_{\mathrm{i}}$ (NCACX) spins, followed by 
a homonuclear dipolar recoupling sequence to transfer spin polarisation between local ${ }^{13} \mathrm{C}$ spins. Numerous homonuclear dipolar recoupling sequences exist, each with specific features that confer advantages for particular applications or experimental conditions, as reviewed by De Paëpe (2012) and Mithu et al. (2013).

An apparent opportunity to condense the acquisition time required for sequential assignment of uniformly labelled solid proteins in this manner is to simultaneously record inter-residue (NCOCX type) and intra-residue (NCACX type) correlations in a single experiment, effectively doubling the information content of typical NCC experiments, and halving the required acquisition time. This type of bidirectional inter- and intra-residue polarisation transfer is exploited frequently in solution-state NMR experiments for protein assignment, such as HNCA (Bax and Ikura 1991) and HNCACB (Grzesiek and Bax 1992a, b). In these liquidstate experiments, polarisation on $\mathrm{N}_{\mathrm{i}}$ spins is simultaneously transferred via the $J$-couplings to both the adjacent $\mathrm{C} \alpha_{\mathrm{i}}$, and the preceding $\mathrm{C} \alpha_{\mathrm{i}-1}$, resulting in a spectrum with both interand intra-residue correlations. For this reason, in favourable cases, either of these experiments can be sufficient to assign the backbone resonances of a protein in a single experiment (Grzesiek and Bax 1992a, b). This bidirectional approach is however rarely encountered in the assignment of solid proteins. This may be attributed to the fact that using the $J$-coupling to transfer polarisation in solid samples is often inefficient compared to dipolar recoupling, particularly at lower MAS rates, due to typically large inhomogeneous linewidths, and short coherence lifetimes. 3D heteronuclear correlation spectroscopy using $J$-based transfers for resonance assignment in solid proteins has been demonstrated previously, where extensive deuteration of samples can help to achieve the required linewidths and coherence lifetimes but is not essential (Linser et al. 2008; Chen et al. 2007).

In terms of using the hetero- and homonuclear dipolar recoupling methods more commonly used in ssNMR assignment methods to simultaneously record inter- and intraresidue correlations, one possibility would be to recouple ${ }^{15} \mathrm{~N}$ spins to ${ }^{13} \mathrm{C}$ spins in a non-selective manner, i.e. $\mathrm{N}-\mathrm{CX}$ rather than NCO or NCA. This method has been demonstrated previously, via a 3D-ZF-TEDOR-DARR experiment using broadband TEDOR rather than specific CP for ${ }^{15} \mathrm{~N}-{ }^{13} \mathrm{C}$ polarisation transfer, simultaneously recoupling $\mathrm{N}-\mathrm{CO}_{\mathrm{i}-1}$, and $\mathrm{N}-\mathrm{C} \alpha_{\mathrm{i}}$ dipolar interactions, before a broadband ${ }^{13} \mathrm{C}$ mixing period using DARR (Daviso et al. 2013). This method has the disadvantage of requiring that the entire protein ${ }^{13} \mathrm{C}$ spectral width ( $\geq 175 \mathrm{ppm}$ ) be acquired in the indirect dimension of a 3D experiment, however, practically necessitating non-uniform sampling (NUS) or deliberate spectral aliasing in order to realise the acquisition timesaving over acquisition of separate NCOCX and NCACX spectra. Alternatively, one could exploit the ${ }^{13} \mathrm{C} /{ }^{13} \mathrm{C}$ homonuclear dipolar recoupling step to simultaneously recouple the $\mathrm{C} \alpha_{i}-\mathrm{CO}_{i-1}$ and $\mathrm{C \alpha}_{\mathrm{i}-1}-\mathrm{CO}_{\mathrm{i}-1}$ dipolar interactions after a specific ${ }^{15} \mathrm{~N}-{ }^{13} \mathrm{C} \mathrm{CP}$ transfer. However, many homonuclear dipolar recoupling sequences used for ${ }^{13} \mathrm{C} /{ }^{13} \mathrm{C}$ recoupling are not able to efficiently simultaneously recouple the smaller $\mathrm{C} \alpha_{i}-\mathrm{CO}_{i-1}$ dipolar interaction, as well as the $\mathrm{C} \alpha_{i-1}-\mathrm{CO}_{\mathrm{i}-1}$ interaction, due to dipolar truncation and/or relayed transfers reducing the intensity of the comparatively long range $\mathrm{C} \alpha_{\mathrm{i}}-\mathrm{CO}_{\mathrm{i}-1}$ correlation (Bayro et al. 2009).

In this paper, we demonstrate that at moderate MAS frequencies $(35 \mathrm{kHz})$, the mixed rotational and rotary resonance (MIRROR) homonuclear recoupling sequence may be incorporated into a 2D- or 3D-NCC correlation experiment to record simultaneously inter- and intra-residue MIRROR-NCOCA spectra by efficiently recoupling both the $\mathrm{C} \alpha_{i-1}-\mathrm{CO}_{\mathrm{i}-1}$ and $\mathrm{C} \alpha_{\mathrm{i}}-\mathrm{CO}_{\mathrm{i}-1}$ dipolar interactions after a specific ${ }^{15} \mathrm{~N}-{ }^{13} \mathrm{C}$ CP transfer step. The MIRROR sequence was chosen as it is a second-order, band-selective homonuclear recoupling sequence, that requires only low ${ }^{1} \mathrm{H}$ rf amplitudes and has been shown to be efficient at moderate MAS frequencies (Scholz et al. 2008). First-order sequences have been utilized to band selectively recouple the $\mathrm{C} \alpha-\mathrm{CO}$ dipolar interaction including band selective homonuclear $\mathrm{CP}$ (BSHCP) (Shi et al. 2014; Chevelkov et al. 2013) and rotational resonance in a tilted rotating frame (R2TR) (Takegoshi et al. 1995; Detken et al. 2001a, b). Such sequences are however more susceptible to dipolar truncation than second order recoupling sequences supressing transfer through the longer range $\mathrm{C} \alpha_{\mathrm{i}}-\mathrm{CO}_{\mathrm{i}-1}$ interaction (Shi et al. 2014; Chevelkov et al. 2013). Broadband homonuclear recoupling sequences such as PDSD and DARR, which operate well at low magnetic fields and spinning frequencies were not chosen, as relayed transfers to sidechain ${ }^{13} \mathrm{C}$ spins would potentially dilute the required spin polarisation transferred from the $\mathrm{CO}$ to the $\mathrm{C} \alpha$. The same is true of broadband second-order sequences that operate efficiently at higher magnetic fields and spinning rates, such as PARIS (Weingarth et al. 2009), SHANGHAI (Hu et al. 2011) and PAR (Lewandowski et al. 2009).

The reintroduction of the second-order terms under the MIRROR condition relies on setting the amplitude of the proton $\mathrm{rf}$ irradiation $\left(v_{1}^{H}\right)$ to a multiple of the spinning speed $\left(v_{r}\right)$ plus or minus the isotropic chemical shift difference between the ${ }^{13} \mathrm{C}$ nuclei (CO to $\left.\mathrm{C} \alpha\right)$ to be recoupled $\left(\Delta v_{i s o}^{C}\right)$, $v_{1}^{H}=n v_{r} \pm \Delta v_{i s o}^{C}$.

As the recoupling condition is dependent on the isotropic chemical shift separation, the transfers are inherently selective. Band-selective transfers offer a number of advantages for backbone assignments, facilitating the directed transfer of magnetization along the protein backbone, whilst restricting the transfer of magnetization to the protein sidechains which would otherwise compromise signal intensity. These 
properties have previously been exploited in assignment schemes which exploit band-selective cross polarization (Chevelkov et al. 2013) and rotational resonance in the tilted rotating frame (Detken et al. 2001). At moderate MAS frequencies $(40 \mathrm{kHz})$ the MIRROR condition has been shown to efficiently recouple the $\mathrm{C} \alpha-\mathrm{CO}$ dipolar interaction to record ${ }^{13} \mathrm{C} /{ }^{13} \mathrm{C}$ correlation spectra in uniformly labelled proteins (Scholz et al. 2008). Several groups have utilised MIRROR to assist in characterization in a variety of systems (Cukkemane et al. 2012; Schuetz et al. 2010a, b; Wasmer et al. 2010). Here, we show that the efficiency of the MIRROR sequence is such that it may be used to recouple both the $\mathrm{C} \alpha_{i-1}-\mathrm{CO}_{\mathrm{i}-1}$ and $\mathrm{C} \alpha_{\mathrm{i}}-\mathrm{CO}_{\mathrm{i}-1}$ dipolar interactions in one bidirectional transfer step. Furthermore, the polarization transfer to $C \alpha_{i}$ and $C \alpha_{i-1}$ spins is relatively uniform throughout the protein sequence, which we attribute to the fixed geometry of the peptide plane regardless of secondary structure. These transfer properties facilitate the reliable, robust observation of both inter- and intra-residue correlations. It is shown that the MIRROR sequence can be incorporated into a 3D-NCOCA experiment, and that the 3D-MIRROR-NCOCA alone can be used to straightforwardly assign the backbone resonances of a microcrystalline sample of the 56-residue model protein GB3, representing a $50 \%$ saving in terms of acquisition time over separate NCOCX and NCACX experiments. Moreover, since MIRROR uses relatively low-power rf fields, it can be combined with low-power $\mathrm{CP}$ and decoupling schemes permitting the construction of a low-power MIRROR-NCOCA experiment where recycle delays are limited by the $\mathrm{T}_{1}$ of the sample rather than the probe duty cycle. Together these properties allow for the efficient acquisition of a 3D data set which allows a complete backbone assignment to be made in a single experiment acquired within $24 \mathrm{~h}$.

\section{Experimental section}

\section{Sample preparation}

Uniformly labelled ${ }^{13} \mathrm{C},{ }^{15} \mathrm{~N}$ GB3 was expressed and purified using the following protocol. A plasmid encoding GB3 was transformed into E. coli BL21(DE3) cells, then grown at $37^{\circ} \mathrm{C}$ in M9 minimal media $\left(6 \mathrm{~g} / \mathrm{l} \mathrm{Na}_{2} \mathrm{HPO}_{4}, 3 \mathrm{~g} / 1 \mathrm{~K}_{2} \mathrm{HPO}_{4}\right.$, $0.5 \mathrm{~g} / \mathrm{l} \mathrm{NaCl}, 1 \mathrm{mM} \mathrm{MgSO}{ }_{4}, 1 \mathrm{mM} \mathrm{CaCl}_{2}$ ) supplemented with $1 \mathrm{~g} / 1{ }^{15} \mathrm{NH}_{4} \mathrm{Cl}, 2 \mathrm{~g} / 1 \mathrm{U}-{ }^{13} \mathrm{C}$-glucose. Protein expression was induced at an $\mathrm{OD}_{600}$ of $\sim 0.7$, with $1 \mathrm{mM}$ isopropyl $\beta$-D-thiogalactoside at $18{ }^{\circ} \mathrm{C}$ for $16 \mathrm{~h}$. Cells were pelleted and resuspended in PBS $(137 \mathrm{mM} \mathrm{NaCl}, 2.7 \mathrm{mM} \mathrm{KCl}, 10 \mathrm{mM}$ $\mathrm{Na}_{2} \mathrm{HPO}_{4}, \mathrm{pH}$ 7.4). The cells were then disrupted by sonication and insoluble material removed by centrifugation. The supernatant was heated to $80^{\circ} \mathrm{C}$ for $10 \mathrm{~min}$ and the insoluble material removed by centrifugation. Ammonium sulphate was added to the supernatant to $60 \%$ saturation and allowed to equilibrate for $2 \mathrm{~h}$, precipitant was again separated by centrifugation. The GB3 was subsequently precipitated in $90 \%$ ammonium sulphate. The pellet was dissolved in $25 \mathrm{mM}$ Tris, $\mathrm{pH} 8$, and desalted with a PD-10 gel filtration column. Anion exchange chromatography performed with $25 \mathrm{mM}$ Tris, pH 8 ( $5 \mathrm{ml}$ HiTrap Q HP), with GB3 eluting at $\sim 0.25 \mathrm{M} \mathrm{NaCl}$. Monomeric GB3 was isolated by gel-filtration (Sephadex 75) with $100 \mathrm{mM} \mathrm{NaCl}, 25 \mathrm{mM}$ bis-tris, $\mathrm{pH}$ 6.5. Peak fractions were pooled and concentrated to $\sim 30 \mathrm{mg} /$ $\mathrm{ml}$ with Generon Vivaspin $5 \mathrm{kDa}$ MWCO filters. Crystallisation was achieved by addition of 2-methyl-2,4-pentanediol to $60 \% \mathrm{v} / \mathrm{v}$ of the total sample volume and allowed to incubate at $0{ }^{\circ} \mathrm{C}$ for $\sim 48 \mathrm{~h}$. The sample was centrifuged into a $1.6 / 1.3 \mathrm{~mm}$ zirconia rotor. A silicone based glue was used to seal the rotor to maintain sample hydration.

\section{Solid-state NMR spectroscopy}

Unless otherwise stated all measurements were conducted at $14.1 \mathrm{~T}$ on an Agilent DD2 $600 \mathrm{MHz}$ NMR spectrometer (Yarnton, UK) equipped with a $1.6 \mathrm{~mm}$ triple resonance magic-angle spinning probe. Samples were spun at $35 \mathrm{kHz}$, and the temperature regulated to $0{ }^{\circ} \mathrm{C}$. For all triple resonance experiments the pulse sequence shown in Fig. 1 was employed. For 'high-power' ${ }^{1} \mathrm{H} /{ }^{15} \mathrm{~N} \mathrm{CP}$ the carrier frequencies were set to the centre of the ${ }^{1} \mathrm{H}(\sim 5 \mathrm{ppm})$ and ${ }^{15} \mathrm{~N}$ $(\sim 120 \mathrm{ppm})$ spectrum. Optimal ${ }^{1} \mathrm{H} /{ }^{15} \mathrm{~N}$ cross-polarization was obtained with a $1.5 \mathrm{~ms}$ contact pulse with a ${ }^{1} \mathrm{H}$ field of $\sim 105 \mathrm{kHz}$ and a ${ }^{15} \mathrm{~N}$ field of $\sim 70 \mathrm{kHz}$. For 'high-power' ${ }^{15} \mathrm{~N}-{ }^{13} \mathrm{C} \mathrm{CP}$ the ${ }^{15} \mathrm{~N}$ carrier frequency was set to the middle of the amide region $(120 \mathrm{ppm})$ and the ${ }^{13} \mathrm{C}$ to the centre of the CO region $(\sim 172 \mathrm{ppm})$. The spin-lock fields were set to $5 / 2$ times the spinning speed, $87.5 \mathrm{kHz}$, for ${ }^{15} \mathrm{~N}$ and $3 / 2$ times the spinning speed, $52.5 \mathrm{kHz}$, for ${ }^{13} \mathrm{C}$. Maximal transfer was observed after $7 \mathrm{~ms}$ cross-polarization. During

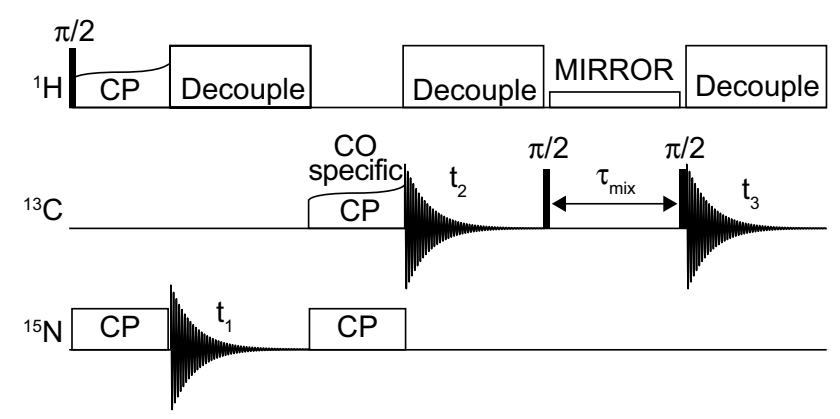

Fig. 1 The 3D-MIRROR-NCOCA pulse sequence employed in this paper. $2 \mathrm{D}-\mathrm{NcoCA}$ data were acquired with no $\mathrm{CO}$ evolution in the indirect dimension, $t_{2}$. 1D-ncoCA spectra used for determining MIRROR conditions and $\mathrm{CO} / \mathrm{C} \alpha$ transfer were acquired with no evolution in either the ${ }^{15} \mathrm{~N}\left(\mathrm{t}_{1}\right)$ or $\mathrm{CO}\left(\mathrm{t}_{2}\right)$ indirect dimensions. All other experimental details are reported in the materials and methods 
${ }^{15} \mathrm{~N} /{ }^{13} \mathrm{C}$ cross-polarization, $135 \mathrm{kHz}$ continuous wave proton decoupling was applied. Under such conditions, magnetization transfer occurred exclusively from the ${ }^{15} \mathrm{~N}$ to the carbonyl carbons. Following transfer from the amide nitrogens to the carbonyls in the protein backbone, magnetization was transferred between carbon sites using a weak rf-field on the protons that satisfied either the dipolar assisted rotary resonance condition $\left(v_{1}^{H}=n v_{\mathrm{r}}\right)$ or the MIRROR condition $\left.\left(v_{1}^{H}=n v_{r} \pm \Delta v_{i s o}^{C}\right)\right)$, where $v_{1}^{H}$ is the proton rf-field amplitude, $\nu_{\mathrm{r}}$ is the rotation frequency and $\Delta v_{i s o}^{C}$ is the isotropic chemical shift difference of a chosen ${ }^{13} \mathrm{C}$ spin-pair. During all evolution periods $120 \mathrm{kHz}$ SPINAL proton decoupling was applied with phase flip angles of $10^{\circ}$ and $5^{\circ}$. All $\pi / 2$ pulses on ${ }^{1} \mathrm{H},{ }^{13} \mathrm{C}$ and ${ }^{15} \mathrm{~N}$ were set to at $2.4,3.2$, and $3.1 \mu \mathrm{s}$ respectively.

For 'low-power' measurements, high-power decoupling was replaced with low-power TPPM decoupling (Kotecha et al. 2007) with a phase alternation of $20^{\circ}$ and a pulse length of $55 \mu \mathrm{s}$. For ${ }^{1} \mathrm{H} /{ }^{15} \mathrm{~N}$ and ${ }^{15} \mathrm{~N} /{ }^{13} \mathrm{C}$ transfers low-power recoupling conditions were established with spin-lock fields of $62 \mathrm{kHz}$ on ${ }^{1} \mathrm{H}$ and $8 \mathrm{kHz}$ on ${ }^{15} \mathrm{~N}$ for ${ }^{1} \mathrm{H} /{ }^{15} \mathrm{~N}$, and $25 \mathrm{kHz}$ on ${ }^{15} \mathrm{~N}$ and $10 \mathrm{kHz}$ on ${ }^{13} \mathrm{C}$ for ${ }^{15} \mathrm{~N} /{ }^{13} \mathrm{C} \mathrm{CP}$ transfers. All 'hard' pulses on ${ }^{1} \mathrm{H},{ }^{13} \mathrm{C}$ and ${ }^{15} \mathrm{~N}$ were kept at $2.4,3.2$, and $3.1 \mu \mathrm{s}$ respectively.

All 2D and 3D experiments were acquired with StatesTPPI phase sensitive detection, employing a ${ }^{15} \mathrm{~N}$ spectral width of $5 \mathrm{kHz}$ and 64 complex points and a $\mathrm{C}_{\mathrm{CO}}$ spectral width of $2.5 \mathrm{kHz}$ and 32 complex points. All spectra were externally referenced to the downfield resonance of adamantane at 40.48 ppm compared to DSS (Morcombe and Zilm 2003). Multidimensional data sets were processed in NMRPipe (Delaglio et al. 1995), prior to analysis and assignment in CCPN Analysis 2.4 (Vranken et al. 2005; Stevens et al. 2011). All processing parameters are given in the corresponding figure legends.

\section{Results and discussion}

Optimal recoupling under the MIRROR condition occurs when the proton $\mathrm{rf}$ amplitude fulfils the condition $v_{1}^{H}=n v_{r} \pm \Delta v_{i s o}^{C}$. Based on the isotropic chemical shifts obtained from the BMRB, (Ulrich et al. 2008) the average frequency separation, $\Delta \bar{v}_{i s o}^{C}$, between the CO and $\mathrm{C} \alpha$ at $14.1 \mathrm{~T}$, the field employed here, is $18.75 \mathrm{kHz}$. This gives rise to theoretical MIRROR conditions at proton rf amplitudes corresponding to nutation frequencies of $16.25,18.75$, 51.25 and $53.75 \mathrm{kHz}$. To identify conditions under which optimal transfer occurs experimentally, the $\mathrm{C} \alpha$ signal intensity obtained after $100 \mathrm{~ms}$ MIRROR mixing was plotted as a function of the MIRROR recoupling field (Fig. 2a). Transfer occurs at two conditions approximately $5 \mathrm{kHz}$ wide that are centred at 18.75 and $50.5 \mathrm{kHz}$ in good agreement
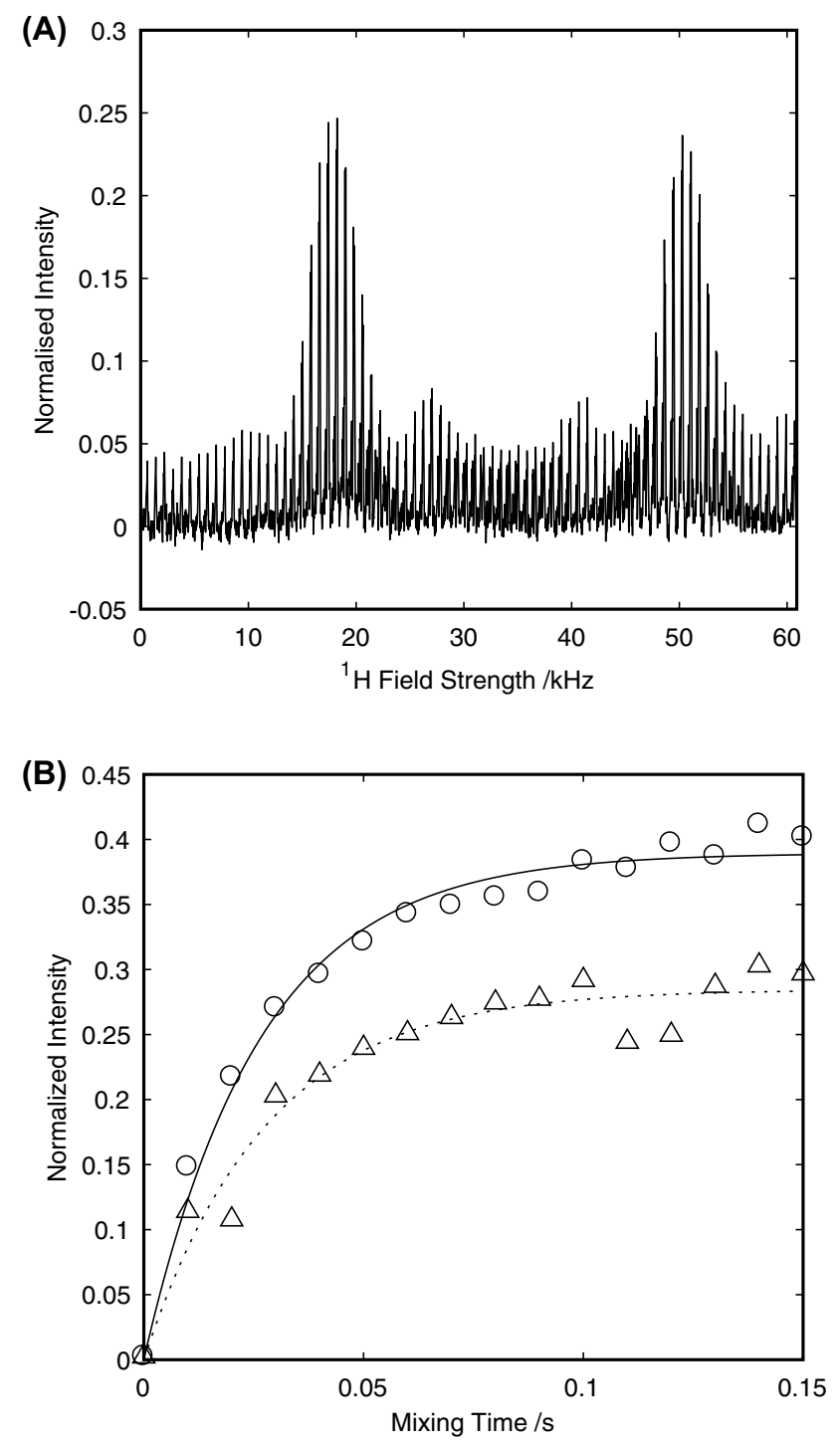

Fig. 2 Signal from $\mathrm{C} \alpha$ region of a 1D-ncoCA spectrum of a microcrystalline GB3 following a $100 \mathrm{~ms}$ period of MIRROR recoupling as a function of the MIRROR recoupling rf-field (a). Build-up of $\mathrm{C} \alpha$ magnetization in a 1D-ncoCA spectrum of microcrystalline GB3 as a function of MIRROR recoupling period for the recoupling condition at $18.5 \mathrm{kHz}$ (solid line with open circle) and $50 \mathrm{kHz}$ (dotted line with open triangle) (b). The amplitudes in A and B are normalised to the integrated intensity of the carbonyl region in the absence of any MIRROR recoupling. Data acquired at $14.1 \mathrm{~T}$ with $35 \mathrm{kHz}$ MAS

with the predicted values $\left(v_{1}^{H}=n v_{r} \pm \Delta v_{i s o}^{C}\right)$. The absence of any transfer at the $\mathrm{n}=1$ DARR condition $(35 \mathrm{kHz})$ should be noted, highlighting the poor efficiency of this technique at moderate spinning frequencies. Comparison of the build-up of magnetization at these two matching conditions (Fig. 2b) shows that maximal transfer occurs with a ${ }^{1} \mathrm{H}$ rf amplitude of $18.75 \mathrm{kHz}$, where transfer occurs under the $\mathrm{n}=0\left(v_{1}^{H}=+\Delta v_{\text {iso }}^{C}\right)$ and $\mathrm{n}=1\left(v_{1}^{H}=v_{r}-\Delta v_{\text {iso }}^{C}\right)$ resonance conditions. Although the superimposition of the two 
matching conditions leads to efficient transfer of magnetization, through the judicious choice of spinning speed the width of the matching condition can be tailored by varying the separation between the $\mathrm{n}=0\left(v_{1}^{H}=+\Delta v_{\text {iso }}^{C}\right)$ and $\mathrm{n}=$ $1\left(v_{1}^{H}=v_{r}-\Delta v_{\text {iso }}^{C}\right)$ conditions. Transfer under the $50.5 \mathrm{kHz}$ matching condition results in a $25 \%$ reduction in the total amount of magnetization transferred from the $\mathrm{CO}$ to the $\mathrm{C} \alpha$, mirroring earlier reports that showed maximal transfer efficiencies at the lower power matching conditions (Scholz et al. 2008). When normalised against the total intensity of the carbonyl region approximately $40 \%$ of the magnetization is transferred from the $\mathrm{CO}$ region to the $\mathrm{C} \alpha$ region of the spectrum, with the bulk of the magnetization transferred within the first $50 \mathrm{~ms}$ of recoupling. The extent of transfer is comparable to other band-selective transfers including bandselective cross-polarization albeit with significantly reduced rf ampliitudes (Chevelkov et al. 2013).

2D-NcoCA data (Fig. 3a) demonstrate that efficient transfer is observed across the $\mathrm{C} \alpha$ region with resonances from 40 to $70 \mathrm{ppm}$ exhibiting similar recoupling efficiencies. This suggests that at $14.1 \mathrm{~T} \mathrm{~B}_{0}$ field strength and $35 \mathrm{kHz}$ spinning speed, the MIRROR recoupling bandwidth is sufficient to actively recouple the entire $\mathrm{CO} / \mathrm{C} \alpha$ envelopes, even in the absence of any modulation of the MIRROR recoupling field. As expected, and in contrast to DARR experiments conducted at lower spinning speeds, little of the magnetization is relayed out to the sidechains following transfer of magnetization from the $\mathrm{CO}$ to $\mathrm{C} \alpha$. Indeed, the resonances not attributable to $\mathrm{C} \alpha$ arise from correlations with ${ }^{13} \mathrm{C}$ sites on amide sidechains. These exhibit a similar chemical shift dispersion and strong dipolar couplings to CO groups. The selective nature of the transfer limits the diffusion of magnetization throughout the protein leading to enhanced intensity in the $\mathrm{C} \alpha$ region of the spectrum.

To assess the utility of the technique at higher field where the variation in $\Delta v_{\text {iso }}^{C}$ will increase with field and the recoupling bandwidth may become comparable to the chemical shift distribution, NcoCA data were acquired at $20 \mathrm{~T}$ (see Supplementary Fig. S1). At the higher field with $50 \mathrm{kHz}$ MAS, transfer is still observed at the $\mathrm{n}=$ $0\left(v_{1}^{H}=+\Delta v_{i s o}^{C}\right)$ and $\mathrm{n}=1\left(v_{1}^{H}=v_{r}-\Delta v_{\text {iso }}^{C}\right)$ condition, although the overall signal sensitivity is lower due to the smaller sample volumes available in the smaller diameter rotors. Intensity is observed from 70 to $40 \mathrm{pm}$, indicating that transfer occurs quite uniformly across the $\mathrm{C} \alpha$ region, even at the high magnetic field, and without the need to resort to amplitude or phase modulation of the MIRROR recoupling rf-field (Scholz et al. 2008; Wittmann et al. 2014).

Closer inspection of the 2D-NcoCA spectrum in Fig. 3a reveals that in addition to the intense resonances arising from the transfer of magnetization from $\mathrm{N}$ to $\mathrm{CO}_{(\mathrm{i}-1)}$ to $\mathrm{C}_{(\mathrm{i}-1)}$ weaker correlations whose intensity is approximately $50 \%$ of the intensity of the $\mathrm{NCOCA}_{(\mathrm{i}-1)}$ are also present for each of the nitrogen sites. Comparison of this data with the corresponding NCA spectrum (Fig. 3b, c) reveals that these weaker resonances correspond to the transfer of magnetization of $\mathrm{N}$ to $\mathrm{CO}_{(\mathrm{i}-1)}$ to $\mathrm{C} \alpha_{(\mathrm{i})}$. Typically at lower spinning speeds using broad-banded transfers we have not systematically observed these long range correlations, presumably due to dipolar truncation effects and loss of intensity as magnetization is transferred out to the amino acid side chains. In this instance though it is apparent that by band selectively recoupling the $\mathrm{CO}$ to the $\mathrm{C} \alpha$ region of the spectra correlations are observed to both the adjacent and more proximal $\mathrm{C} \alpha$ 's. Given the fixed geometry surrounding the peptide bond, the distances between the $\mathrm{CO}_{(\mathrm{i}-1)}$ and the $C \alpha_{(\mathrm{i}-1)}$ and $C \alpha_{(\mathrm{i})}$ remain constant at 1.52 and $2.43 \AA$ respectively, irrespective of the backbone conformation of the protein. Given this fixed geometry, it is expected that the transfer of magnetization from the $\mathrm{CO}_{(\mathrm{i}-1)}$ to the $\mathrm{C} \alpha_{(\mathrm{i}-1)}$ and $\mathrm{C \alpha}_{(\mathrm{i})}$ would be similar for all sites within the proteins, something that is qualitatively apparent in the 2D-NcoCA spectrum of GB3 (Fig. 3a, b) where in well resolved regions
Fig. 3 2D-NcoCA spectrum of microcrystalline GB3 using $100 \mathrm{~ms}$ MIRROR transfer from transfer of magnetization from the $\mathrm{CO}$ to $\mathrm{C} \alpha$ (a, blue), superimposition of the NcoCA (blue) with the NCA spectrum (green) (b), and the NCA spectrum (c, green). Tie lines in (b) highlight the presence of connectivities between intense peaks arising from the $\mathrm{NCOCA}_{(\mathrm{i}-1)}$ and the weaker peaks arising from the $\mathrm{NCOCA}_{(\mathrm{i})}$ transfer. Data acquired at $14.1 \mathrm{~T}$ with $35 \mathrm{kHz}$ MAS

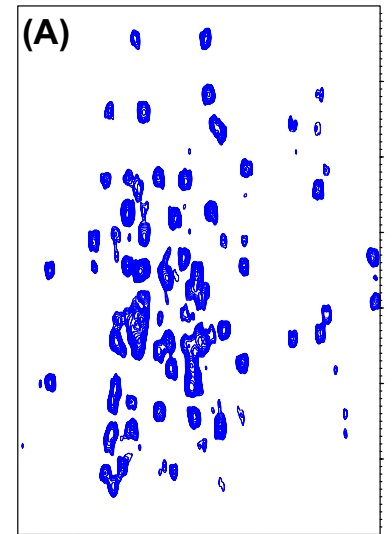

$\begin{array}{lllll}65 & 60 & 55 & 50 & 45\end{array}$ $\delta\left({ }^{13} \mathrm{C}\right) / \mathrm{ppm}$

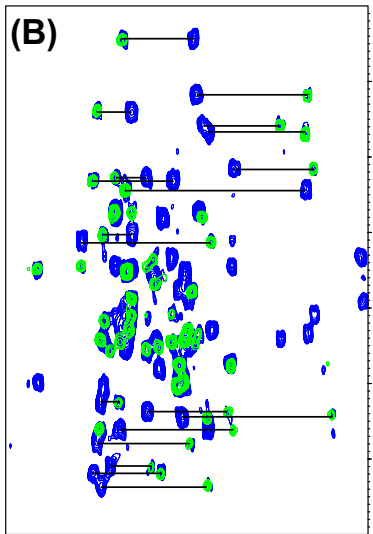

$\begin{array}{lllll}65 & 60 & 55 & 50 & 45\end{array}$ $\delta\left({ }^{13} \mathrm{C}\right) / \mathrm{ppm}$

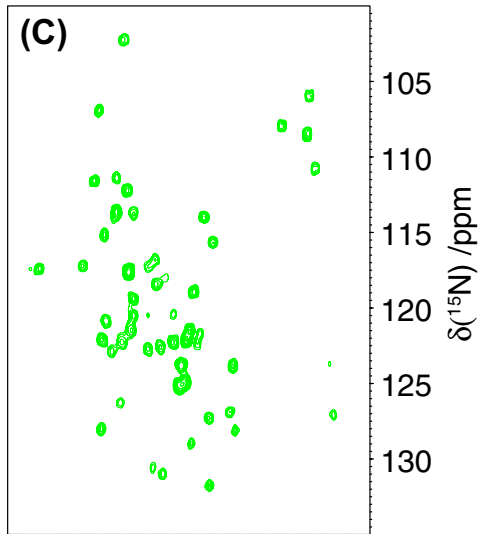

$\begin{array}{lllll}65 & 60 & 55 & 50 \quad 45\end{array}$ $\delta\left({ }^{13} \mathrm{C}\right) / \mathrm{ppm}$ 
each nitrogen resonance possesses pairs of $\mathrm{C} \alpha$ resonances irrespective of its location within the protein. A quantitative analysis of the magnetization transfer (Fig. 4, Supplementary Table S1) from the $\mathrm{CO}$ to the two $\mathrm{C} \alpha$ sites reveals that the rate of transfer to the two sites is similar. Time constants of between 20 and $40 \mathrm{~ms}$ are observed when exchange is modelled as an exponential process. This suggests that the observed difference in resonance intensities is not due to differences in transfer rates, but rather to differences in the extent to which magnetization is transferred. The more distant $\mathrm{C} \alpha_{(\mathrm{i})}$ site typically exhibits an intensity of $40-60 \%$ of that observed for the direct transfer to the $\mathrm{C}_{(\mathrm{i}-1)}$ site (Fig. 3, Supplementary Table S1).

In the context of a 2D-NcoCA experiment, the presence of the coupling from the $\mathrm{CO}_{(\mathrm{i}-1)}$ to the $\mathrm{C} \alpha_{(\mathrm{i})}$ and $\mathrm{C} \alpha_{(\mathrm{i}-1)}$ sites allows nitrogens in the peptide backbone to be simultaneously correlated to the (i) and (i-1) residues in a single experiment. The presence of additional peaks in the NCOCA spectrum has previously been observed when employing broad-banded homonuclear recoupling sequence such as PDSD and in such instances viewed unfavourably as it can lead to increased spectral crowding (Chevelkov et al. 2013). This spectral crowding can in part be overcome through the acquisition of 3D-NCOCA spectra (Supplementary Fig. S3). Importantly though, the MIRROR transfer results in systematic and efficient transfer from the $\mathrm{CO}_{(\mathrm{i}-1)}$ to $\mathrm{C} \alpha_{(\mathrm{i})}$ and $\mathrm{C} \alpha_{(\mathrm{i}-1)}$ sites with little/
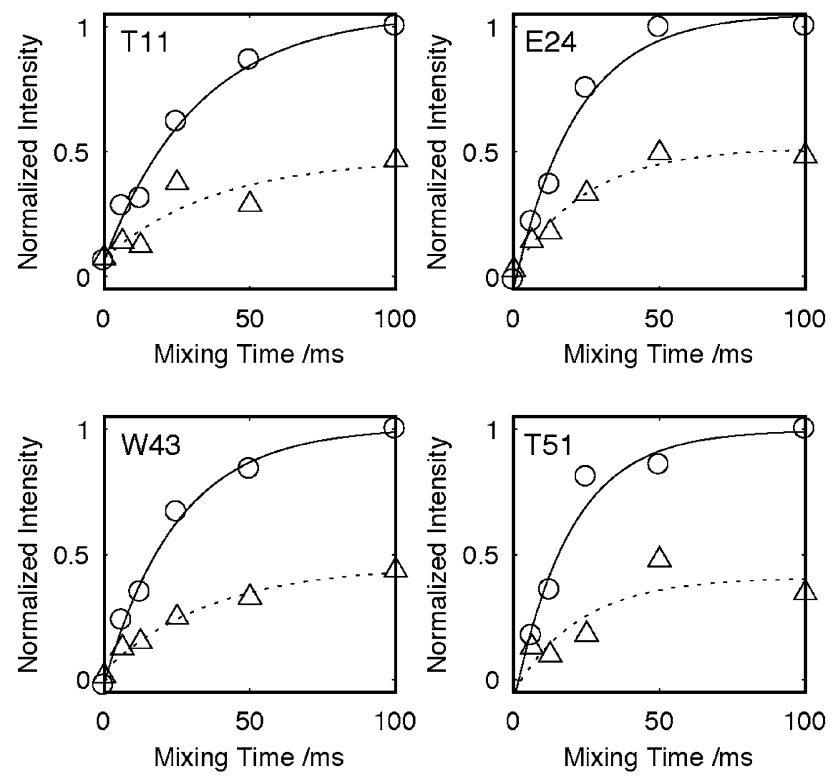

Fig. 4 Plots showing the build-up of magnetization following transfer from $\left.\mathrm{CO}_{(\mathrm{i}-1}\right)$ to $\mathrm{C} \alpha_{(\mathrm{i}-1)}$ (solid line with open circle) and $\mathrm{CO}_{(\mathrm{i}-1)}$ to $\mathrm{C} \alpha_{(\mathrm{i})}$ (dotted line with open triangle) for selected resonances. Data integrated from the corresponding 2D-NcoCA spectra of a microcrystalline preparation of GB3. All data normalised to the maximum intensity of the $\mathrm{C} \alpha_{(\mathrm{i}-1)}$, and fitted to an exponential build-up. Data acquired at $14.1 \mathrm{~T}$ with $35 \mathrm{kHz}$ MAS no coupling to other sites. This simplifies the analysis of the data as the resulting $\mathrm{C} \alpha$ strip plots contains only two resonances, the stronger showing the correlation between $\mathrm{N}_{(\mathrm{i})}$ and $\mathrm{C} \alpha_{(\mathrm{i}-1)}$ and the weaker that between $\mathrm{N}_{(\mathrm{i})}$ and $\mathrm{C} \alpha_{(\mathrm{i})}$ (Supplementary Fig. S3 and Fig. 5). This facilitates the assignment process as all the connectivities necessary for a backbone assignment are present in a single data set. For those familiar with solution NMR protein backbone assignments, the resulting spectrum can be thought of as analogous to the liquid state HNCA (Kay et al. 1990; Farmer et al. 1992; Grzesiek and Bax 1992), albeit with an inversion of the relative intensities of the $\mathrm{C} \alpha$ resonances of the current and preceding amino acid. The spectra can therefore be interpreted in a similar manner to solutionstate HNCA data, 'walking' through the $\mathrm{C} \alpha$ slices to sequentially assign the protein backbone.

The low rf amplitudes employed for MIRROR recoupling offer significant advantages for the analysis of protein samples, since rf-induced sample heating is greatly limited. The use of weak rf-fields permits a reduction in recycle delay, whose minimum value is normally limited by the duty cycle of the probe/spectrometer under high-power conditions. Furthermore, MIRROR recoupling and the assignment scheme highlighted above is compatible with the low-power decoupling and CP schemes (Kotecha et al. 2007; Vijayan et al. 2009; Ernst et al. 2003) and PACC schemes (Wickramasinghe et al. 2008; Ishii et al. 2001).

To demonstrate the potential savings in acquisition time we have incorporated the MIRROR recoupling into an NCOCA experiment where all polarization transfer and decoupling steps have been replaced by low-power equivalents (Fig. 5), allowing the recycle time to be reduced from $2.5 \mathrm{~s}$ to that which is optimal for the $\mathrm{T}_{1}$ of the sample (700 ms). During all evolution times, SPINAL decoupling (Fung et al. 2000) was replaced by low-power TPPM (Kotecha et al. 2007), allowing a reduction of ${ }^{1} \mathrm{H}$ rf amplitudes from 135 to $8.75 \mathrm{kHz}$. Low-power $\mathrm{CP}$ conditions can also be identified by arraying both ${ }^{1} \mathrm{H}$ and ${ }^{15} \mathrm{~N}$ field strengths during the $\mathrm{CP}$ period to locate a suitable low-power condition, with efficient transfer from ${ }^{1} \mathrm{H}$ to ${ }^{15} \mathrm{~N}$ achieved using double quantum CP at the $\mathrm{n}=2$ condition (Meier 1992; Laage et al. 2009; Demers et al. 2010), with a ${ }^{1} \mathrm{H}$ spin-lock field of $62 \mathrm{kHz}$ and a ${ }^{15} \mathrm{~N}$ of $8 \mathrm{kHz}$, whilst optimal transfer from ${ }^{15} \mathrm{~N}$ to ${ }^{13} \mathrm{C}$ obtained at the $\mathrm{n}=1$ double quantum $\mathrm{CP}$ condition with a ${ }^{13} \mathrm{C}$ spin-lock field of $10 \mathrm{kHz}$ and a ${ }^{15} \mathrm{~N}$ field of $25 \mathrm{kHz}$. A comparison of the peak intensities of these conditions with the high-power variants is given in Fig. S2. As is apparent, the replacement of polarization transfer steps with low-power equivalents has little effect on the overall resolution and sensitivity of the overall experiment, even at these moderate spinning frequencies. The only noticeable difference between the low-power and high-power variants 


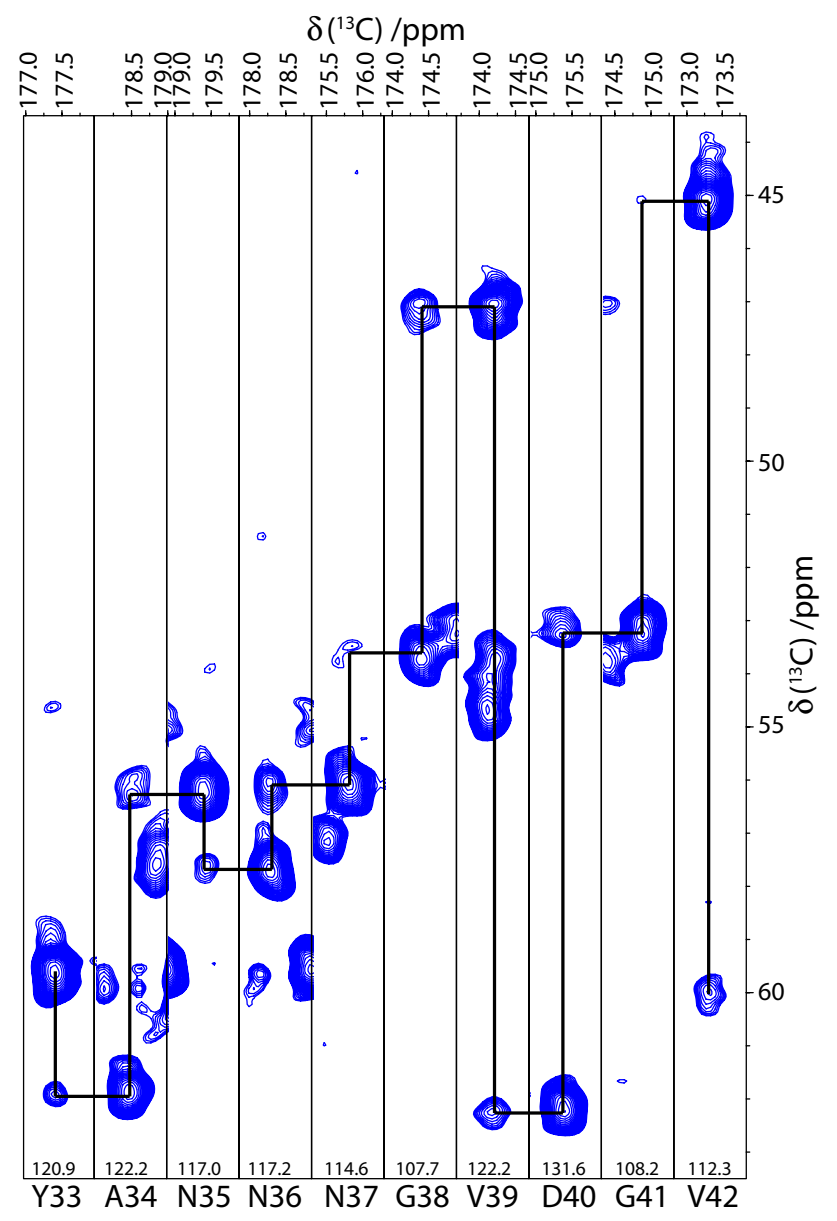

Fig. 5 Strip plot of low-power 3D-NCOCA experiment for connectivities between residues Y33 to V42 with tracing through backbone. Chemical shift for each ${ }^{15} \mathrm{~N}$ plane is given at the bottom of each slice. Large peaks in each nitrogen dimension are the $\mathrm{CO}_{(\mathrm{i}-1)}$ to $\mathrm{C} \alpha_{(\mathrm{i}-1)}$, while the smaller peak is the $\mathrm{CO}_{(\mathrm{i}-1)}$ to $\mathrm{C} \alpha_{(\mathrm{i})}$ correlation

is the absence of intensity between 38 and $42 \mathrm{ppm}$ which we attribute to the sidechains of the acidic amino acids.

The reduction in recycle time allowed a single 3D-NCOCA experiment, providing the complete backbone assignment of the 56 residue protein GB3, to be performed in as little as $12.5 \mathrm{~h}$. This may be compared with $45 \mathrm{~h}$ for the equivalent high-power experiment. A comparison of the data quality shown in Supplementary Fig. S3. Further time saving may be made through the use of paramagnetic dopants to accelerate $\mathrm{T}_{1}$ relaxation, allowing a further reduction in recycle time.

\section{Conclusion}

In summary, we demonstrate that MIRROR recoupling enables the bidirectional transfer of magnetization from the $\mathrm{CO}$ site to the adjacent $\mathrm{C} \alpha$, and to the $\mathrm{C} \alpha$ of the preceding amino acid. In the context of a 3D-NCOCA experiment this doubles the information content providing correlations from $\mathrm{CO}\left({ }_{\mathrm{i}-1}\right)$ to both $\mathrm{C} \alpha_{(\mathrm{i}-1)}$ and $\mathrm{C} \alpha_{(\mathrm{i})}$. The presence of these two correlations permits the sequential assignment of the protein backbone without the need for conducting multiple 3D experiments. Furthermore, the low rf amplitudes required for the most efficient MIRROR recoupling conditions enable the construction of 'low-power' experiments facilitating further reductions in the data acquisition time.

Acknowledgements MMJ was supported by an EPSRC studentship (EP/J00121X/1) and by the European Research Council (291044HYPERSINGLET). PTFW and MC were supported by EPSRC Grant (EP/M023664/1). The UK $850 \mathrm{MHz}$ solid-state NMR Facility used in this research was funded by EPSRC and BBSRC (contract reference PR140003), as well as the University of Warwick including via part funding through Birmingham Science City Advanced Materials Projects 1 and 2 supported by Advantage West Midlands (AWM) and the European Regional Development Fund (ERDF). Collaborative assistance from the $850 \mathrm{MHz}$ Facility Manager (Dinu Iuga, University of Warwick) is acknowledged.

Open Access This article is distributed under the terms of the Creative Commons Attribution 4.0 International License (http://creativecommons.org/licenses/by/4.0/), which permits unrestricted use, distribution, and reproduction in any medium, provided you give appropriate credit to the original author(s) and the source, provide a link to the Creative Commons license, and indicate if changes were made.

\section{References}

Agarwal V, Penzel S, Szekely K, Cadalbert R, Testori E, Oss A, Past J, Samoson A, Ernst M, Bockmann A, Meier BH (2014) De Novo 3D structure determination from sub-milligram protein samples by solid-state $100 \mathrm{kHz}$ MAS NMR spectroscopy. Angew Chem Int Ed 53:12253-12256

Andreas LB, Jaudzems K, Stanek J, Lalli D, Bertarello A, Le Marchand T, Paepe DCD, Kotelovica S, Akopjana I, Knott B, Wegner S, Engelke F, Lesage A, Emsley L, Tars K, Herrmann T, Pintacuda $\mathrm{G}$ (2016) Structure of fully protonated proteins by proton-detected magic-angle spinning NMR. P Natl Acad Sci USA 113:9187-9192

Barbet-Massin E, Pell AJ, Retel JS, Andreas LB, Jaudzems K, Franks WT, Nieuwkoop AJ, Hiller M, Higman V, Guerry P, Bertarello A, Knight MJ, Felletti M, Le Marchand T, Kotelovica S, Akopjana I, Tars K, Stoppini M, Bellotti V, Bolognesi M, Ricagno S, Chou JJ, Griffin RG, Oschkinat H, Lesage A, Emsley L, Herrmann T, Pintacuda G (2014) Rapid proton-detected NMR assignment for proteins with fast magic angle spinning. J Am Chem Soc 136:12489-12497

Bax A, Ikura M (1991) An efficient 3D NMR technique for correlating the proton and $15 \mathrm{~N}$ backbone amide resonances with the $\alpha$-carbon of the preceding residue in uniformly $15 \mathrm{~N} / 13 \mathrm{C}$ enriched proteins. J Biomol NMR 1:99-104

Bayro MJ, Huber M, Ramachandran R, Davenport TC, Meier BH, Ernst M, Griffin RG (2009) Dipolar truncation in magic-angle spinning NMR recoupling experiments. J Chem Phys 130:114506

Chen L, Kaiser JM, Polenova T, Yang J, Rienstra CM, Mueller LJ (2007) Backbone assignments in solid-state proteins using J-based 
3D Heteronuclear correlation spectroscopy. J Am Chem Soc 129:10650-10651

Chevelkov V, Shi C, Fasshuber HK, Becker S, Lange A (2013a) Efficient band-selective homonuclear CO-CA cross-polarization in protonated proteins. J Biomol NMR 56:303-311

Chevelkov V, Shi C, Fasshuber HK, Becker S, Lange A (2013b) Efficient band-selective homonuclear CO-CA cross-polarization in protonated proteins. J Biomol NMR 56:303-311

Chevelkov V, Giller K, Becker S, Lange A (2013c) Efficient CO-CA transfer in highly deuterated proteins by band-selective homonuclear cross-polarization. J Magn Reson 230:205-211

Chevelkov V, Shi C, Fasshuber HK, Becker S, Lange A (2013d) Efficient band-selective homonuclear CO-CA cross-polarization in protonated proteins. J Biomol NMR 56:303-311

Cukkemane A, Nand D, Gradmann S, Weingarth M, Kaupp UB, Baldus M (2012) Solid-state NMR [C-13,N-15] resonance assignments of the nucleotide-binding domain of a bacterial cyclic nucleotide-gated channel. Biomol NMR Assign 6:225-229

Daviso E, Eddy MT, Andreas LB, Griffin RG, Herzfeld J (2013) Efficient resonance assignment of proteins in MAS NMR by simultaneous intra- and inter-residue 3D correlation spectroscopy. J Biomol NMR 55:257-265

De Paepe G (2012) Dipolar recoupling in magic angle spinning solid-state nuclear magnetic resonance. Ann Rev Phys Chem 63:661-684

Delaglio F, Grzesiek S, Vuister GW, Zhu G, Pfeifer J, Bax A (1995) Nmrpipe-a multidimensional spectral processing system based on unix pipes. J Biomol NMR 6:277-293

Demers JP, Vijayan V, Becker S, Lange A (2010) Tailored low-power cross-polarization under fast magic-angle spinning. J Magn Reson 205:216-223

Detken A, Hardy EH, Ernst M, Kainosho M, Kawakami T, Aimoto S, Meier BH (2001a) Methods for sequential resonance assignment in solid, uniformly C-13, N-15 labelled peptides: quantification and application to antamanide. J Biomol NMR 20:203-221

Detken A, Ernst M, Meier BH (2001b) Towards biomolecular structure determination by high-resolution solid-state NMR: assignment of solid peptides. Chimia (Aarau) 55:844-851

Ernst M, Samoson A, Meier BH (2003) Low-power XiX decoupling in MAS NMR experiments. J Magn Reson 163:332-339

Farmer BT, Venters RA, Spicer LD, Wittekind MG, Muller LA (1992) Refocused and optimized HNCA-increased sensitivity and resolution in large macromolecules. J Biomol NMR 2:195-202

Fung BM, Khitrin AK, Ermolaev K (2000) An improved broadband decoupling sequence for liquid crystals and solids. J Magn Reson 142:97-101

Grzesiek S, Bax A (1992a) An efficient experiment for sequential backbone assignment of medium-sized isotopically enriched proteins. J Magn Reson 99:201-207

Grzesiek S, Bax A (1992b) Improved 3D triple-resonance NMR techniques applied to a 31-kDa protein. J Magn Reson 96:432-440

Higman VA, Flinders J, Hiller M, Jehle S, Markovic S, Fiedler S, van Rossum BJ, Oschkinat H (2009) Assigning large proteins in the solid state: a MAS NMR resonance assignment strategy using selectively and extensively C-13-labelled proteins. J Biomol NMR 44:245-260

Hu BW, Lafon O, Trebosc J, Chen Q, Amoureux JP (2011) Broadband homo-nuclear correlations assisted by $\mathrm{H}-1$ irradiation for bio-molecules in very high magnetic field at fast and ultra-fast MAS frequencies. J Magn Reson 212:320-329

Ishii Y, Yesinowski JP, Tycko R (2001) Sensitivity enhancement in solid-state C-13 NMR of synthetic polymers and biopolymers by H-1 NMR detection with high-speed magic angle spinning. J Am Chem Soc 123:2921-2922
Kay LE, Ikura M, Tschudin R, Bax A (1990) 3-Dimensional tripleresonance NMR-spectroscopy of isotopically enriched proteins. J Magn Reson 89:496-514

Kotecha M, Wickramasinghe NP, Ishii Y (2007) Efficient low-power heteronuclear decoupling in C-13 high-resolution solid-state NMR under fast magic angle spinning. Magn Reson Chem 45:S221-S230

Laage S, Sachleben JR, Steuernagel S, Pierattelli R, Pintacuda G, Emsley L (2009) Fast acquisition of multi-dimensional spectra in solid-state NMR enabled by ultra-fast MAS. J Magn Reson 196:133-141

Lewandowski JR, De Paëpe G, Eddy MT, Struppe J, Maas W, Griffin RG (2009) Proton assisted recoupling at high spinning frequencies. J Phys Chem B 113:9062-9069

Linser R, Fink U, Reif B (2008) Proton-detected scalar coupling based assignment strategies in MAS solid-state NMR spectroscopy applied to perdeuterated proteins. J Magn Reson 193:89-93

Marchetti A, Jehle S, Felletti M, Knight MJ, Wang Y, Xu ZQ, Park AY, Otting G, Lesage A, Emsley L, Dixon NE, Pintacuda G (2012) Backbone assignment of fully protonated solid proteins by $1 \mathrm{H}$ detection and ultrafast magic-angle-spinning NMR spectroscopy. Angew Chem Int Ed 51:10756-10759

Meier BH (1992) Cross polarization under fast magic angle spinningthermodynamical considerations. Chem Phys Lett 188:201-207

Mithu VS, Bakthavatsalam S, Madhu PK (2013) C-13-C-13 homonuclear recoupling in solid-state nuclear magnetic resonance at a moderately high magic-angle-spinning frequency. PLOS ONE 8:e50504

Morcombe CR, Zilm KW (2003) Chemical shift referencing in MAS solid state NMR. J Magn Reson 162:479-486

Pauli J, Baldus M, van Rossum B, de Groot H, Oschkinat H (2001) Backbone and side-chain C-13 and N-15 signal assignments of the alpha-spectrin $\mathrm{SH} 3$ domain by magic angle spinning solid-state NMR at 17.6 T. Chembiochem 2:272-281

Ravotti F, Wälti MA, Güntert P, Riek R, Böckmann A, Meier BH (2016) Solid-state NMR sequential assignment of an Amyloid- $\beta(1-42)$ fibril polymorph. Biomol NMR Assign 10:269-276

Schnell I (2005) Merging concepts from liquid-state and solid-state NMR spectroscopy for the investigation of supra- and biomolecular systems. Curr Anal Chem 1:3-27

Scholz I, Huber M, Manolikas T, Meier BH, Ernst M (2008) MIRROR recoupling and its application to spin diffusion under fast magicangle spinning. Chem Phys Lett 460:278-283

Schuetz A, Wasmer C, Habenstein B, Verel R, Greenwald J, Riek R, Böckmann A, Meier BH (2010a) Protocols for the sequential solid-state NMR spectroscopic assignment of a uniformly labeled $25 \mathrm{kDa}$ protein: HET-s(1-227). Chembiochem 11:1543-1551

Schuetz A, Wasmer C, Habenstein B, Verel R, Greenwald J, Riek R, Bockmann A, Meier BH (2010b) Protocols for the sequential solid-state NMR spectroscopic assignment of a uniformly labeled $25 \mathrm{kDa}$ protein: HET-s(1-227). Chembiochem 11:1543-1551

Shi CW, Fasshuber HK, Chevelkov V, Xiang SQ, Habenstein B, Vasa SK, Becker S, Lange A (2014) BSH-CP based 3D solid-state NMR experiments for protein resonance assignment. J Biomol NMR 59:15-22

Sperling LJ, Berthold DA, Sasser TL, Jeisy-Scott V, Rienstra CM (2010) Assignment strategies for large proteins by magic-angle spinning NMR: the 21-kDa disulfide-bond-forming enzyme DsbA. J Mol Biol 399:268-282

Stevens TJ, Fogh RH, Boucher W, Higman VA, Eisenmenger F, Bardiaux B, van Rossum BJ, Oschkinat H, Laue EDA (2011) A software framework for analysing solid-state MAS NMR data. J Biomol NMR 51:437-447

Su YC, Sarell CJ, Eddy MT, Debelouchina GT, Andreas LB, Pashley CL, Radford SE, Griffin RG (2014) Secondary structure in the 
core of amyloid fibrils formed from human beta(2)m and its truncated variant delta N6. J Am Chem Soc 136:6313-6325

Takegoshi K, Nomura K, Terao T (1995) Rotational resonance in the tilted rotating-frame. Chem Phys Lett 232:424-428

Theint T, Nadaud PS, Surewicz K, Surewicz WK, Jaroniec CP (2017) $13 \mathrm{C}$ and $15 \mathrm{~N}$ chemical shift assignments of mammalian Y145Stop prion protein amyloid fibrils. Biomol NMR Assign 11:75-80

Ulrich EL, Akutsu H, Doreleijers JF, Harano Y, Ioannidis YE, Lin J, Livny M, Mading S, Maziuk D, Miller Z, Nakatani E, Schulte CF, Tolmie DE, Wenger RK, Yao HY, Markley JL (2008) BioMagResBank. Nucleic Acids Res 36:D402-D408

Vijayan V, Demers JP, Biernat J, Mandelkow E, Becker S, Lange A (2009) Low-power solid-state NMR experiments for resonance assignment under fast magic-angle spinning. Chemphyschem 10:2205-2208

Vranken WF, Boucher W, Stevens TJ, Fogh RH, Pajon A, Llinas P, Ulrich EL, Markley JL, Ionides J, Laue ED (2005) The CCPN data model for NMR spectroscopy: development of a software pipeline. Proteins-Struct Funct Bioinform 59:687-696

Wang SL, Parthasarathy S, Xiao YL, Nishiyama Y, Long F, Matsuda I, Endo Y, Nemoto T, Yamauchi K, Asakura T, Takeda M, Terauchi
T, Kainosho M, Ishii Y (2015) Nano-mole scale sequential signal assignment by H-1-detected protein solid-state NMR. Chem Commun 51:15055-15058

Wasmer C, Zimmer A, Sabate R, Soragni A, Saupe SJ, Ritter C, Meier BH (2010) Structural similarity between the prion domain of HET-s and a homologue can explain amyloid cross-seeding in spite of limited sequence identity. J Mol Biol 402:311-325

Weingarth M, Demco DE, Bodenhausen G, Tekely P (2009) Improved magnetization transfer in solid-state NMR with fast magic angle spinning. Chem Phys Lett 469:342-348

Wickramasinghe NP, Shaibat MA, Jones CR, Casabianca LB, de Dios AC, Harwood JS, Ishii Y (2008) Progress in C-13 and H-1 solidstate nuclear magnetic resonance for paramagnetic systems under very fast magic angle spinning. J Chem Phys 128:052210

Wiegand T, Gardiennet C, Ravotti F, Bazin A, Kunert B, Lacabanne D, Cadalbert R, Guntert P, Terradot L, Bockmann A, Meier BH (2016) Solid-state NMR sequential assignments of the N-terminal domain of HpDnaB helicase. Biomol NMR Assign 10:13-23

Wittmann JJ, Hendriks L, Meier BH, Ernst M (2014) Controlling spin diffusion by tailored rf-irradiation schemes. Chem Phys Lett 608:60-67 